\title{
BRINCADEIRAS INFANTIS COMO ESPAÇOS DE INVENÇÃO DO TEMPO DE VIDA QUE NOMEAMOS INFÂNCIA
}

\author{
Renata Aparecida Carbone Mizusaki* \\ Cleomar Ferreira Gomes**
}

\begin{abstract}
Resumo: Os modos de pertencer a um espaço social variam de cultura para cultura e ao longo da história. Há uma multiplicidade de sentidos, valores e simbolismos que circunda as representações construídas por uma comunidade em torno dos lugares ocupados pelas crianças, uma rede cujas tramas são tecidas e significadas cotidianamente, alinhavadas pelo conhecimento partilhado ou sedimentado pelas/nas relações de socialização, educação, poder, economia e políticas. Há um emaranhado de ideias sentidas, percebidas, que trazem uma história a essas relações de vivência, de estar em coletivos humanos que amparam a construção das identidades. As crianças brasileiras, como parte desses coletivos, têm um lugar nesses espaços sociais e culturais que thes possibilitam habitar o mundo. Qual é esse lugar? Como elas se percebem nesses espaços? Como se constroem como produtoras de pensamento e de culturas nesses lugares em que se encontram? Discutir essas questões parece ser uma ação importante e necessária tanto do ponto de vista social e político quanto educacional. Nessa direção, este artigo pretende abordar como as crianças, por meio de suas brincadeiras, constroem sua existência social e cultural (re)fazendo a grafia do cotidiano de modo inventivo e singular. De caráter qualitativo, numa imersão bibliográfica, apresenta as possibilidades lúdico-criativas, traduzidas e interpretadas pelas crianças como um lugar de habitar-se em suas infâncias, de escavar identidades que Ihes dão sentido na produção de seus espaços, culturas, saberes e lugares no mundo.
\end{abstract}

Palavras-chave: Brincadeiras. Infâncias. Crianças. Espaços sociais. Culturas.

"Se você não sabe de onde vem, você

será sempre uma criança" (Cícero).

\footnotetext{
* Pedagoga e Mestre em Educação pela Universidade Estadual Paulista Júlio de Mesquita Filho (FCT/Unesp - Presidente Prudente-SP); Doutora em Educação pela Universidade Federal de Mato Grosso (PPGE/IE/UFMT); Professora Adjunta do Departamento Acadêmico de Ciências da Educação da Universidade Federal de Rondônia (Dacie/Unir/Nilhena - RO). Líder do Cirandeiras Grupo de Pesquisas e Estudos das Crianças, Folclore, Brincadeiras e Culturas Infantis. E-mail: renatamizusaki@hotmail.com

** Licenciado em Educação Fisica; Mestre em Educação pela UFMT; Especialista em Ciências do Jogo pela Université de Paris-Nord, Villetaneuse/Paris, França; Doutor em Educação pela USP; Pós-Doutor em Socioantropologia da Educação pela Universidade Federal Fluminense; Professor Titular da Faculdade de Educação Fisica e do Programa de Mestrado e Doutorado em Educação da Universidade Federal de Mato Grosso (UFMT); Lider do Gepcol - Grupo de Pesquisas Corporeidade e Ludicidade. E-mail: gomescleo.cg@gmail.com
} 


\section{NOTAS DE COMEÇAR: ORIGENS}

Simon Goldhill (2007), ao narrar o espírito grego que encarna as raizes de muitos de nossos ritos e rituais ${ }^{1}$ cotidianos e a importância de sabermos profundamente de nossas origens para (re)conhecermo-nos, refere-se às palavras de Cícero para reportar a falta da "autoridade e poder" da criança nas culturas romana e grega. 0 autor indica-nos com isso que guardamos resquícios que inviabilizam o afastamento por completo de nossas ancestralidades culturais para abrigar-nos em um mundo com uma cultura totalmente nova. 0 presente guarda a sombra do passado, que nos assusta ou que nos impulsiona a novas criações. De toda forma, podemos tomar o discurso de Cícero para nos questionarmos acerca dos pensamentos que ocupam nosso imaginário e nossas práticas sociais hoje: Qual é o lugar da criança em nossa cultura? Onde habitam as infâncias brasileiras? De que modo as crianças expressam seu poder em nossa cultura? Em quais espaços? Como elas se percebem nesses espaços? Como se constroem como produtoras de pensamento e de culturas nesses lugares em que se encontram?

A potência daquela fala do estadista ainda nos ressoa, nos alcança quando interpretamos que "na melhor das hipóteses, uma criança é um adulto ainda não formado, um adulto incapacitado. Este é o tipo de vida com o qual Cícero nos ameaça" (GOLDHILL, 2007, p. 9). Se, por um lado, estamos construindo espaços de fala, de participação das crianças, perguntamo-nos, por outro, acerca do que temos deixado como herança sociocultural, tradições, representações que sustentam, como origem e pertencimento, as crianças que chegam à nossa sociedade para que elas possam saber de suas raizes: "Quais são os dispositivos sociais, educativos e culturais com os quais dialogamos com as crianças no processo de construção de suas infâncias?". Essas e outras questões moventes aparecem e nos convidam a refletir sobre as tradições, concepções que temos edificado e sobre direções novas que as crianças nos apresentam a trilhar.

É por esses encontros na busca da compreensão da ocupação dos espaços sociais e do imaginário que os abriga que caminhamos em direção de encontrar os sentidos interpretados pelas crianças para os modos pelos quais elas habitam suas identidades na cultura brasileira. Suspeitamos que esse trajeto de suspensão epistêmica seja a própria brincadeira infantil.

As brincadeiras das crianças acenam como um espaço fenomênico de ação, de criação, de invenção, de imaginário que ancoram nuclearmente a cultura produzida comunalmente pelas crianças. É uma ritualidade, uma liturgia lúdica, aceita honrosamente pelos/as jogado-

1 - A partir de Claude Rivière (1996), podemos entender os rituais como um complexo conjunto de ações, linguagens, expressões, intencionalmente provocados e com valor simbólico evidente para quem os pratica repetidamente. Os ritos, como parte componente dos rituais, são os padrões estereotipados, automatizados (mas com valor para quem os produz) realizáveis durante as cerimônias. 
res/as, ancestralmente ligados/as pelo brincar. É ciranda que junta, alicerça a habitação corpórea das crianças, conclamadas por elas mesmas a exercer uma autoridade sobre a história, a memória coletiva, reinventando as hierarquias de poder, de conhecimento.

Muitas vezes uma metáfora estrangeira, as brincadeiras infantis hibridizam as relações de poder, de pensamento, de ordenamento corporal para reivindicar um espaço singular que ladeia a cultura adulta, sem dela desvincular-se. É uma arena de heróis que não disputam interesses, mas que convidam à travessia de realidades, uma narrativa nova da vida. Nessa arqueologia lúdica dos espaços, a criança se afirma, cria políticas outras, reverencia o tempo que não tem fim e transforma as relações humanas em um lugar de potência.

\section{POLITICA, ECONOMIA, PODER E INFÂNCIAS}

As infâncias podem ser traduzidas como um tempo reinventado na experiência das crianças que o investem de sentido, de criação, expandindo e transcendendo esse tempo ao tempo da produção.

É uma relação que não pode ser medida pelo tempo cronológico ou social, apenas, mas adiantando-se ao passado e inventando brechas para alongar-se do futuro, inteira-se na intensidade do presente; constitui-se na participação ativa em um tempo outro, ou, como descreve Walter Kohan (2008), um "tempo aiônico", que é, segundo esse autor, o tempo do renascimento, do esperançar autêntico, do corpo novo de vida, de saber.

As infâncias são construídas pelas crianças como um mundo em comunicação com outras formas de cultura e de poder, investido de autoria, resistência, inventividade.

Em suas integrações com o tempo, com a infância, as crianças relacionam-se com o mundo que as cerca e com seus pares, num processo de socialização, como atravessamento, ou seja, é na relação de constituição com o outro por meio do afeto, do pensamento em movimento, no provimento de novas relações com o tempo, com o espaço outro de criação e inovação de sentidos e subjetividades, que as crianças constroem a infância. Passa pela simbolização ritual constituído por meio da presença do outro, com quem aprende, dialoga e se torna inteira.

Essas relações com o outro e com o tempo são produzidas em condições concretas de existência.

Para Manuel Sarmento (2008), Jens Qvortrup (2010) e Romilson Siqueira (2011), a infância não é uma fase transitória e nem uma condição natural, mas uma categoria "social do tipo geracional" construida histórica e socialmente.

Qvortrup (2010) afirma que a infância faz parte da estrutura cultural, política e econômica de uma sociedade e sofre os impactos da economia e da política nos meios de produção da vida tais como os adultos, ainda que não tenha participação plena ou direta nas decisões dessas relações mais amplas. 
Segundo Qvortrup (2010, p. 786),

\begin{abstract}
A noção de infância não considera a criança individual, e sim arranjos legais, espaciais, temporais e institucionais voltados às crianças em uma determinada sociedade. Podemos falar de infância como um fenômeno social, como uma construção social ou algo parecido. Sua forma ou arquitetura depende de parâmetros como economia, tecnologia, cultura, atitudes adultas etc., e da interação entre eles. Visto que esses parâmetros mudam e assumem continuamente novas configurações, a infância nunca é a mesma - mesmo que seja da mesma natureza.
\end{abstract}

Qvortrup (2010, p. 791) chama-nos a atenção para as questões políticas e econômicas que afetam (in)diretamente a vida das crianças. Segundo ele, a política como orientação ideológica preserva os interesses dos adultos e não os das crianças, atuando ora de modo "protecionista", ora com "indiferença estrutural". Outras esferas da vida pública, de acordo com o autor, se incluem nesse rol, como as demarcações legais, os dispositivos econômicos e culturais, pois esses mecanismos sociais alcançam os modos de produzir as infâncias, seja relevando as desigualdades, seja impondo condições de vivência.

Para o autor,

De um ponto de vista positivo, o esforço da exclusão ajudava a proteger as crianças dos perigos do mundo moderno; de um negativo, era um projeto ilusório e duvidoso. Ilusório porque as crianças fazem parte desse mundo amplo em muitos, muitos aspectos; duvidoso, e talvez até mesmo contraproducente, no sentido de esconder as crianças num tipo de "limbo analítico", o que impediu pesquisadores e outros de atentarem às macroforças, que são da mais alta importância, potencialmente, para as condições de vida das crianças (OVORTRUP, 2011, p. 202).

Com essas palavras, Qvortrup (2011) nos lembra da necessária vigilância acerca dos impactos políticos e da economia na realidade das crianças, as mais afetadas.

Nessas condições, as infâncias são assim espaços comunicantes dos modos de existir em uma sociedade e podem revelar desigualdades no que se refere ao acesso aos bens materiais fundamentais para as crianças de diferentes idades e classes sociais.

Na mesma direção, Rita Marchi e Manuel Sarmento (2017) enunciam as relações econômicas e políticas como definidoras das infâncias. Ao discutirem como as infâncias vão sendo "normatizadas"2, especialmente no século XX, a partir da Convenção Internacional sobre os

2 - Por normatização os autores definem: "o conjunto de regras e disposições jurídicas e simbólicas (explícitas e implicitas) que regulam a posição das crianças na sociedade e orientam as relações entre elas e os adultos, nos contextos de interações face a face, nas instituições e nas políticas de infância" (MARCHI; SARMENTO, 2017, p. 953). 
Direitos da Criança em que se apresenta um "modelo de infância", os autores destacam os abismos sociais aportados nas condições históricas da constituição moderna de infância. Para Marchi e Sarmento (2017, p. 955), o documento se tornou um importante referencial para os países signatários incorporarem políticas locais de atendimento às crianças a partir de princípios universalizantes pautados, segundo os autores, em uma perspectiva protecionista e liberal tendo como resultado o que Sarmento nomeou de "'administração simbólica' da infância". Com isso ficam mais marcadas as desigualdades econômicas e sociais dos diferentes paises, ressaltando o caráter marginal e excludente das crianças pobres no tangente ao acesso e à garantia de seus direitos civis mais básicos.

Por isso,

[...] a última década tem evidenciado a profunda contradição entre a normatividade infantil produzida pela modernidade, a partir de sua matriz ocidental cêntrica, e as condições de vida das crianças vítimas das profundas desigualdades geradas na sociedade contemporânea, caracterizada pela globalização hegemônica do modelo de capitalismo financeiro. Se essa normatividade incorpora uma concepção de bem-estar das crianças, assente em direitos de proteção, provisão e participação, a realidade não apenas contraria aquilo que os documentos jurídicos reguladores preconizam - o que, a liás, sempre aconteceu num quadro de profunda contradição entre a lei escrita e a lei na prática - como, de modo mais grave, o que na presente década parece emergir é um abandono não apenas da retórica jurídica, mas também da consideração das crianças como sujeitos específicos de direitos (MARCHI; SARMENTO, 2017, p. 960).

A superação das discrepâncias na narrativa jurídica e na escrita da vida concreta percebida em diferentes dispositivos sociais requer um olhar historicamente situado sobre as infâncias, o estudo profundamente qualificado de suas condições reais de vida e a propositura participada pelas crianças de possibilidades de intervenção social e política.

Muitas são as marcas históricas e sociais que dão relevo à constituição periférica da maioria das crianças latino-americanas, brasileiras. Elas são muitas. Ocupam lugares distintos, habitam corpos múltiplos.

A despeito desse necessário olhar histórico sobre as crianças e as infâncias brasileiras, Cohn (2005) e Del Priore (2015) reforçam a importância de estudos que traduzam as narrativas infantis escondidas entre o mundo adulto e as imagens de poder dele advindas, pois revelam os traços, as formas de inserção, de produção de saberes e participação infantis. São preciosos, ainda, porque interpretam as relações sociais, educacionais, políticas, os ritos, os símbolos que entoam a historicidade com que as crianças foram se constituindo para serem, hoje, percebidas dos modos como são.

Nessa direção, a Sociologia da Infância, conforme Sarmento (2008), tem se estabelecido como um campo profícuo no estudo aprofundado das infâncias. Atenta às aberturas trazidas 
pelo olhar sobre essas condições de vida das crianças, a Sociologia da Infância, segundo Manuel Sarmento (2008), tem centralizado a criança nos espaços sociais de fala, de pensamento e de cultura. Ressignificando o lugar de marginalidade histórica em que a criança esteve guardada em espaços de socialização e de cuidado, essa disciplina mostra-nos quão fundamental é conhecer e compreender a vida das crianças para além de seus espaços privados, ampliando-os para diversos espaços públicos e institucionais participados pelas crianças (SARMENTO, 2008).

Por essas iluminuras nos estudos das condições materiais de produção concreta das infâncias de diferentes culturas e contextos sociais, econômicos e políticos, a Sociologia da Infância, para Sarmento (2008), por intermédio da ação infantil, abre um campo de possibilidades de participação infantil nesses espaços estruturantes da vida aportando a importância de compreensão alargada e reflexiva do lugar simbólico e social das crianças em suas sociedades.

Além disso, modificações na compreensão simbólica das infâncias e dos espaços sociais habitados por meninos e meninas indicam os diferentes projetos politicos e sociais a eles/ elas voltados, o que, por sua vez, corrobora a necessidade da inserção social das crianças em seus contextos culturais. Percebidas ou silenciadas em seus direitos, em suas práticas sociais e coletivas, as diversas imagens de infâncias, como dinâmica temporal e espacial em elaboração, relevam o imaginário coletivo e os projetos de nação para uma categoria social cuja geracionalidade afeta os sentidos, as simbologias e os trajetos da análise antropológica, histórica e sociológica que asseguram seu "caráter permanente", como conceitua Qvortrup (2011).

Atravessar essas dinâmicas sociais que traduzem diferentes realidades vivenciadas pelas crianças, a precariedade de suas condições de existência, as violências cotidianas na extirpação de seus direitos exige de nós o reconhecimento da pluralidade das infâncias e dos lugares sociais por elas ocupadas em um movimento de tensionamento das forças produtoras das desigualdades. Além disso, requer que atentemos às produções infantis na reinvenção desses lugares a partir da ação da criança na reordenação cultural dos sentidos, dos significados criados, autoralmente, pelas crianças. Esse exercício duplo de reconhecimento compreensivo da real situação das diferentes crianças e infâncias pelo mundo e da ação infantil sobre essa realidade, já iniciado pelos estudos sociais das infâncias, é, portanto, cada vez mais pertinente.

Como forma de ação infantil, as "culturas infantis de pares", definidas por Willian Corsaro (2011, p. 128) como "um conjunto estável de atividades ou rotinas, artefatos, valores e preocupações que as crianças produzem ou partilham em interação com as demais", anunciam modos próprios que as crianças utilizam para participar de uma interpretação particular da realidade que as abriga, isto é, uma "reprodução interpretativa". Corsaro (2011) enfatiza ainda a importância da participação das crianças nas rotinas que são tecidas social e cultural- 
mente, como forma de inserção e de pertencimento tanto nas culturas de pares como na cultura adulta. Em razão disso,

\begin{abstract}
Nessa perspectiva de reprodução interpretativa, as atividades de crianças com seus pares e sua produção coletiva de uma série de culturas de pares são tão importantes quanto sua interação com adultos. Além disso, alguns elementos da cultura de pares afetam também as rotinas adulto-criança na familia e em outras configurações culturais. Vemos, então, que tanto a participação infantil nas rotinas adulto-criança na família e em outros ambientes, quanto nas rotinas das culturas de pares, influenciam sua participação como membro nas culturas infantis e no mundo adulto (CORSARO, 2011, p. 129).
\end{abstract}

As culturas infantis então dimensionam diferentes formas de participação das crianças, bem como lançam luz aos pensamentos priorizados nas condutas coletivas, tanto nas relações com adultos quanto com outras crianças.

Como parte fundante dessas culturas infantis, as brincadeiras das crianças são espaços e tempos de reivindicação epistemológica da criança ao mesmo tempo que são a vitrine das expectativas sociais projetadas na compreensão das infâncias por meio do brinquedo como dispositivo cultural. As brincadeiras das crianças são, também, um modo de acesso ao universo percebido pela criança e de aproximação cultural, política e econômica de suas condições materiais de existência.

Participar das brincadeiras das crianças é ter a possibilidade de aprender com elas sobre seus modos de estar no mundo e de compreender suas perspectivas. Para professores/as e adultos, essa é uma oportunidade de entender como as crianças criam seu lugar no mundo, sua cultura. Como elaboram suas arqueologias de cidadania, de expressão corpórea, de conhecimentos.

A brincadeira é, assim, espaço de constituição, de afirmação de identidade, de construção de novas realidades.

\title{
A BRINCADEIRA COMO LUGAR DE CONSTITUIÇÃO DA CULTURA DAS CRIANÇAS: AS FUNDAÇÕES DO ABRIGO SOCIAL
}

As brincadeiras infantis são parte fundamental de condição de existência do mundo infantil. Elas compõem um universo simbólico, narrativo, lúdico e de corporeidade que integra diferentes formas de pensamentos e formas sinestésicas, cognitivas, de expressão, simbolismo e de culturas que caracterizam as práticas das crianças numa realidade por elas construida e interpretada. Ocorrem em cirandas coletivas de grupos nomeados, mesmo que momentaneamente, para aquela liturgia lúdica em que imprimem papéis e lugares sociais 
que coreografam o cotidiano roteirizado pelas crianças. É, portanto, também, uma estratégia de sobrevivência ante as imposições da realidade produzida concreta e cotidianamente.

Para Johan Huizinga (2014), Jean Château (1987) e Gilles Brougère (2004, 2010), o jogo acontece numa realidade à parte, não tem qualquer retribuição, é uma atividade voluntária e improdutiva e é motivada pelo prazer que provoca: "E a essência do espírito lúdico é ousar, correr riscos, suportar a incerteza e a tensão. A tensão aumenta a importância do jogo, e esta intensificação permite ao jogador esquecer que está apenas jogando" (HUIZINGA, 2014, p. 59).

Ainda que os adultos brinquem e que nomeiem de outros modos suas brincadeiras, as brincadeiras são atividades endereçadas às crianças de modo não natural, ou seja, as crianças, segundo Brougère $(2004,2010)$, não nascem sabendo brincar, elas aprendem a brincar com as outras crianças ou, como diria Château (1987), com os mais velhos, à sua sombra. Para Château (1987), como tradição herdada dos que vieram primeiro, os mais velhos introduzem os que chegam à ciranda lúdica na ritualidade do jogo e da brincadeira. Assim, ao incorporarem as práticas que compõem o ofício lúdico, é possível integrar aquela fraternidade brincante.

Segundo Gomes (2001), as crianças são tributárias das brincadeiras, da liberdade que elas evocam, diferentemente do jogo, que exige outras configurações espaciais e principalmente exige o emprego de regras.

Metáfora do cotidiano interpretado pelas crianças, as brincadeiras carregam, segundo Brougère (1998), uma "significação social" que é feita na/pela presença do outro a partir da cultura compartilhada no jogo. Para o autor, o jogo supõe uma cultura específica ao jogo ou uma "cultura lúdica".
A cultura lúdica é, antes de tudo, um conjunto de procedimentos que permitem tornar o jogo possivel. Com Bateson e Goffman consideramos efetivamente o jogo como uma ativi- dade de segundo grau, isto é, uma atividade que supõe atribuir às significações de vida comum um outro sentido, o que remete à idéia de faz-de-conta, de ruptura com as signi- ficações da vida quotidiana. Dispor de uma cultura lúdica é dispor de um certo número de referências que permitem interpretar como jogo atividades que poderiam não ser vistas como tais por outras pessoas (BROUGÈRE, 1998, p. 105).

A cultura lúdica é então, segundo o autor, esse ritual lúdico com um conjunto de sentidos, conteúdos, esquemas, estruturas precisas, específicas, próprias do jogo jogado pelas crianças. É um encontro cimentado pela cultura do jogo que junta as crianças para brincar. Esse ajuntamento infantil que partilha de símbolos lúdicos comuns é que caracteriza o simbolismo compartilhado.

Parte fundamental que possibilita a continuidade da brincadeira e do jogo, o brinquedo é também elemento de cultura. Nessas composições, o brinquedo possibilita à criança o 
acesso ao universo cultural, simbólico, que ancora as relações entre as crianças e entre essas e os adultos.

A função do brinquedo pode ser assim definida: "o brinquedo propõe à criança uma atividade fundamental na nossa sociedade: o uso de um suporte não humano para ter acesso a certos aspectos da cultura" (BROUGĖRE, 2004, p. 263).

0 brinquedo aparece assim, como o diz Brougère (2004), como o mediador de representações que tomam a forma que a criança dá à sua realidade imaginada enquanto brinca; ele serve aos usos infantis e às metamorfoses necessárias para a criação de enredos que garantam a continuidade e a coerência interna da brincadeira, segundo o autor. Brincadeira e brinquedo compõem um cenário que descreve a imprecisão do futuro.

Nas palavras de Brougère (2004, p. 7):

As crianças brincam praticamente com os mesmos brinquedos, desde que tenham acesso a eles, porém, em cada um dos paises, elas são confrontadas com um conjunto, com um parque de brinquedos diferente. Além do mais, o uso do brinquedo, desde o consumo à destruição passando pela brincadeira, se inscreve numa cultura especifica que difere conforme o sexo, o meio social e, é claro, a cultura da criança, cultura essa que varia, entre outras coisas, conforme a nação.

Assim, ainda que sejam intensas as pressões exercidas pelo mercado produtor de brinquedos, é a interpretação, o sentido e a simbologia que a criança constrói com e pelo brinquedo que edificam a brincadeira. A criança, segundo Brougère (2010), não é uma receptora passiva desses dispositivos lúdicos. 0 autor considera que na produção dos brinquedos estão envolvidas concepções que integram um conceito de infância e de criança que deve estar em consonância com os interesses, contextos e símbolos presentes no cotidiano e nas brincadeiras das crianças. Assim, "Conceber e produzir um brinquedo é transformar em objeto uma representação, um mundo imaginário ou relativamente real. Se partirmos de uma função, conceber um brinquedo é introduzi-lo numa ficção e numa lógica simbólica" (BROUGÈRE, 2010, p. 17).

Imagens e símbolos abarcam, portanto, um objeto que capta um espírito lúdico com a finalidade de corresponder ao desejo infantil de brincar. No entanto, na incerteza da brincadeira é a imaginação que direciona e transforma o uso do brinquedo. A ciranda das crianças é que decide qual a função do brinquedo de acordo com sua simbologia e imagens provisórias; de outro modo, "uma análise puramente funcional do objeto, em vez de dissolver a imagem, correria o risco de conduzir a um esquecimento de como é que ela dá significação ao objeto" (BROUGĖRE, 2010, p. 23).

Brinquedos, brincadeiras unem as crianças em espaços de construção, de metáforas da vida, de criação de mundos em que as diferenças não são geradoras de desigualdades, de 
hierarquias. Brincando a criança se (a)firma em uma terra povoada pelo imaginário em que ela também tem poder e autoridade sobre seus destinos.

\section{ALGUMAS ÚLTIMAS PALAVRAS PARA DAR OUTROS INÍCIOS A PENSAMENTOS E IDEIAS}

As crianças habitam lugares diferentes nas sociedades, na história, na economia e na política. Há abismos que separam as crianças em diferentes partes do mundo, fazendo com que as infâncias sejam vividas, sentidas, experienciadas de modos distintos pelas crianças. No Brasil, essas habitações infantis são também marcadas pelas desigualdades profundas entre as crianças que vivem nas cidades, para as crianças da zona rural, para as crianças indígenas, quilombolas, brancas, negras, orientais, as pobres, enfim, há uma multiplicidade que não cabe na "normatização da infância" (MARCHI; SARMENTO, 2017). 0 acesso aos bens sociais, materiais e culturais criam sendas que tornam ainda mais evidentes as diferenças sociais.

Por sua vez, as crianças nos ensinam que é possivel construir fundações culturais singulares à revelia ou em resistência a uma sociedade que Ihes cerceia a autoridade por meio da institucionalização de seus saberes, fazendo-as diminutas em presença social nos espaços de fala, do discurso, da afirmação das linguagens. Pelas vias lúdicas, as crianças cirandam suas tradições, transmitem uma herança cultural corporal brincada ritualmente nas arenas históricas do poder do imaginário, da criação, da ruptura e, também, do encontro, com os quais erguem suas civilizações infantis, criam suas comunidades com quem fraternizam os jogos, formando assim outras raizes ancestrais, genealógicas. Fundam seus lugares de existência no mundo. Identificam-se. Imprimem suas leis, seus modos de viver autenticamente e de tecer suas formas de existência e de criação.

Devemos nos ocupar em compreender as multiplicidades de infâncias existentes, não de forma idealizada, mas a partir de suas condições reais de (sobre)vivência, em suas culturas, com seus saberes. Potencializar as várias vozes, os olhares, os discursos das crianças em espaços participativos se torna fundamental na configuração de suas necessidades e expectativas, já que

[...] um determinado tipo de infância, sendo considerado norma, não somente desclassifica todos os outros tipos no plano ideal, mas, mais grave, exclui no plano empírico - da realidade social cotidiana - determinadas crianças dos direitos que Ihes são internacionalmente assegurados. [...]. Desse modo, práticas e concepções de crianças que se afastam da normatividade definida pelas classes e grupos sociais dominantes podem levar a excluir certas crianças do próprio estatuto social reconhecido da infância: tematizados como 
"não crianças", os meninos de rua, por exemplo, sofrem dupla exclusão, dos direitos sociais básicos e do valor simbólico inerente ao seu reconhecimento como crianças de jure e de facto (MARCHI; SARMENTO, 2017, p. 957).

O lugar das crianças em nossa sociedade deve ser o lugar da afirmação, da presença, da fala, das linguagens, da cidadania vivida e não apenas lida nos textos jurídicos. As crianças devem ocupar espaços de autonomia e participação ativa, a partir de suas necessidades e expectativas estabelecidas em diálogo com a cultura por elas produzidas, vivenciadas e experimentadas. Lugar de pertencimento político, social, cultural, de multiplicidades, de acesso institucional aos bens (i)materiais produzidos historicamente. Nas brincadeiras e nos jogos, nas culturas infantis, as crianças criam essas possibilidades de fundarem lugares afirmativos, que se fazem na e pela presença do outro, com quem comungam conhecimentos, identidades. Pela brincadeira as crianças nos ensinam também sobre sua cultura, suas condições de vida, sobre desigualdades, sobre a construção de outras realidades, de outros mundos; habitáveis de possibilidades e de encontros com economias e políticas de outras naturezas. Escavam fundações de socialização e de educação que colocam no centro a travessia para outras civilidades.

Sustentando-nos em nossas raízes e com os olhos voltados para o presente e o futuro, devemos aprender a estabelecer novas epistemologias, novas culturas, discursos e origens junto com as crianças ou estaremos fadados/as a conviver com a sombra perturbadora das palavras de Cícero.

\title{
Children's play as spaces for the invention of the life time we name childhood
}

\begin{abstract}
The ways of belonging to a social space varies from culture to culture and throughout history. There is a multiplicity of meanings, values and symbolisms that surround the representations built by a community around the places occupied by children, a network whose plots are woven and signified daily, aligned by the knowledge shared or sedimented by/in the relationships of socialization, of education, of power, economics, and politics. There is a tangle of ideas but felt, perceived, that bring a history to these relationships of experience, of being in human collectives that support the construction of identities. Brazilian children, as part of these collectives, have a place in these social and cultural spaces, which enable them to inhabit the world. What is this place? How do they perceive themselves in these spaces? How are they built as producers of thought and cultures in these places where they find themselves? Discussing these issues seems to be an important and necessary action, both from a social, political, and educational point of view. In this direction, this article intends to approach how children, through their games, build their social and cultural existence doing another did write of everyday life in an inventive and singular way. Discussing these issues seems to be an important and necessary action, both from a social and educational point of view. In this direction, this article intends to approach how children, through their
\end{abstract}


games, build their social, political, and cultural existence (re) engineering, the geography of everyday life in an inventive and singular way. Of a qualitative character, in a bibliographic immersion, it presents the playful-creative possibilities, translated, and interpreted by children as a place to live in their childhoods, to excavate identities that give them meaning in the production of their spaces, cultures, knowledge and places in world.

Keywords: Plays. Childhoods. Children. Social spaces. Cultures.

\section{REFERÊNCIAS}

BROUGÈRE, G. A criança e a cultura lúdica. Revista da Faculdade de Educação, v. 24, n. 2, p. 103-116, jul./dez. 1998. Disponivel em: https://www.scielo.br/scielo.php?pid=S0102-25551998000200007Etscript=sci_arttext\&tIng. Acesso em: $1^{\circ}$ ago. 2020.

BROUGÈRE, G. Brinquedos e companhia. São Paulo: Cortez, 2004.

BROUGÈRE, G. Brinquedo e cultura. 8. ed. São Paulo: Cortez, 2010.

BUJES, M. I. E. 0 fio e a trama: as crianças nas malhas do poder. Educação e Realidade, Porto Alegre, v. 25, n. 1, p. 25-44, jan./jun. 2000.

CHÂTEAU, J. O jogo e a criança. São Paulo: Summus, 1987.

COHN, C. Antropologia da criança. 3. reimp. Rio de Janeiro: Zahar, 2005.

CORSARO, W. A. Sociologia da infância. 2. ed. Porto Alegre: Artmed, 2011.

DEL PRIORE, M. (org.). História das crianças no Brasil. 7. ed. São Paulo: Contexto, 2015.

GOLDHILL, S. Amor, sexo \&t tragédia: como gregos e romanos influenciam nossas vidas até hoje. Rio de Janeiro: Zahar, 2007.

GOMES, C. F. Meninos e brincadeiras de Interlagos: um estudo etnográfico da ludicidade. 2001. Tese (Doutorado em Educação) - Universidade de São Paulo, São Paulo, 2001.

HUIZINGA, J. Homo ludens: o jogo como elemento da cultura. São Paulo: Perspectiva, 2014.

KOHAN, W. O. Infância e filosofia. In: SARMENTO, M.; GOUVEA, M. C. S. de (org.). Estudos da infância: educação e práticas sociais. Petrópolis: Vozes, 2008. p. 40-61.

MARCHI, R. de C.; SARMENTO, M. Infância, normatividade e direitos das crianças: transições contemporâneas. Educação e Sociedade, Campinas, v. 38, n. 141, p. 951-964, out./dez. 2017. Disponivel em: https://www.scielo.br/pdf/es/v38n141/1678-4626-es-es0101-73302017175137.pdf. Acesso em: 31 jul. 2020.

OVORTRUP, J. Infância e política. Cadernos de Pesquisa, São Paulo, v. 40, n. 141, p. 777-792, set./dez. 2010. Disponivel em: publicações.fcc.org.br/ojs/index.php/cp/article/view/147/146. Acesso em: 2 jun. 2019. 
QVORTRUP, J. Nove teses sobre a "infância como um fenômeno social". Pro-Posições, Campinas, v. 22, n. 1, p. 199-211, 2011.

RIVIĖRE, C. Os ritos profanos. Petrópolis: Vozes, 1996.

SARMENTO, M. J. Sociologia da Infância: correntes e confluências. In: SARMENTO, M.; GOUVEA, M. C. S. de (org.). Estudos da infância: educação e práticas sociais. Petrópolis: Vozes, 2008. p. 17-39.

SIQUEIRA, R. M. Do silêncio ao protagonismo: por uma leitura crítica das concepções de infância e criança. 2011. Tese (Doutorado em Educação) - Universidade Federal de Goiás, Goiânia, 2011. Disponivel em: https://ppge.fe.ufg.br/up/6/o/TESE_Romilson_Martins_Siqueira.pdf?1335451613. Acesso em: 22 maio 2019. 